\title{
What factors contribute to high mechanical strength of tabia? Case study of the tabia from coastal forts sites at Zhejiang, China
}

\author{
Cuisong Zhang ${ }^{1}$, Bingjian Zhang ${ }^{1,2^{*}}\left(\mathbb{D}\right.$, Biao Cui $^{3}$ and Guocong Lin ${ }^{4}$
}

\begin{abstract}
Tabia is one of the most widely used construction materials in ancient China. In this work, the tabia samples from three coastal defense fort sites at Zhejiang Province, China, we analyzed to determine their component composition and physiochemical properties. The results show that these tabia samples exhibited high compressive strength, which could be as high as 4-9 MPa. Furthermore, the systematic analysis demonstrated that the high compressive strength was related to the following factors: (1) a suitable mass ratio of sand, lime, and clay; (2) an appropriate sand particle size ratio; and (3) the formation of hydrated calcium silicate (C-S-H). Moreover, sticky rice was also detected in the tabia samples. These findings are fundamentally important, which could be beneficial to further study of the craftsmanship of the coastal defense forts and could further provide essential guidance for the protection and restoration of the tabia relics.
\end{abstract}

Keywords: Tabia, Coastal defense fort, Compressive strength, C-S-H, Sticky rice

\section{Introduction}

Tabia, a mixture of clay, lime, and sand, was widely used in the urban wall construction [1-3], tombs [4-6], and water conservancy facilities [7] in ancient China for its super mechanical properties. Zhang and co-workers have discovered starch in the mortar sample of a tomb in Eastern Han Dynasty (25-220 AD) in Xuzhou, Jiangsu, China [8]. About 1500 years ago, organic additives such as sticky rice, tung oil, egg white, sugar, blood, and plant vine juice have been widely applied to improve mechanical properties of the tabia [9]. After the Second Opium War (1856-1860 AD), the construction of the tabia coastal defense forts in China's coastal area began, and the sticky rice tabia coastal defense forts were also constructed [10]. Xu Jiagan's "Outline of Coastal Defense" recorded the craftsmanship of sticky rice tabia coastal defense forts. The proportion of lime:clay:sand of the

\footnotetext{
*Correspondence: zhangbiji@zju.edu.cn

${ }^{1}$ Department of Cultural Heritage and Museology, Zhejiang University,

Hangzhou 310028, People's Republic of China

Full list of author information is available at the end of the article
}

tabia used in building the forts was 5:3:2. After being well mixed with sticky rice soup, it was pounded from eight inches to two inches thick. The finished material was said to be as hard as iron [11]. Due to long-term exposure to the natural environment, these tabia coastal defense forts were greatly subjected to water erosion, wind erosion, freezing and thawing erosion and temperature changes, which have caused some damages such as spalling and collapse. Therefore, it is in urgent to protect these tabia coastal defense forts [12-16]. When the tabia coastal defense fort sites are to be subjected to the necessary insitu replacement and repair work, the "original materials and original craftsmanship" needs to be done at the early stage. Therefore, understanding the relationship between the strength, raw material ratio, and construction methods is fundamentally important not only for studying historical of building materials, but also providing insights into the construction of tabia, and further severing for all purpose of restoring tabia coastal defense fort sites.

In recent years, there have been many studies on the mechanical properties and material composition of tabia coastal defense forts in China. Li et al. [17] investigated
Springer Open

(c) The Author(s) 2020. This article is licensed under a Creative Commons Attribution 4.0 International License, which permits use, sharing adaptation, distribution and reproduction in any medium or format, as long as you give appropriate credit to the original author(s) and the source, provide a link to the Creative Commons licence, and indicate if changes were made. The images or other third party material in this article are included in the article's Creative Commons licence, unless indicated otherwise in a credit line to the material. If material is not included in the article's Creative Commons licence and your intended use is not permitted by statutory regulation or exceeds the permitted use, you will need to obtain permission directly from the copyright holder. To view a copy of this licence, visit http://creativeco mmons.org/licenses/by/4.0/. The Creative Commons Public Domain Dedication waiver (http://creativecommons.org/publicdomain/ zero/1.0/) applies to the data made available in this article, unless otherwise stated in a credit line to the data. 
the tabia coastal defense forts in Dagu, Tianjin city using XRD, XRF, and SEM-EDS methods. They found that the formula of clay, lime, and sand for "Hai" fort is 1:2:1, while the formula of clay and lime for "Wei" fort is 3:1. Ruan et al. [18] compared mechanical properties between the tabia coastal defense forts in Jiaoshan, Jiangsu province with simulated tabia samples made by traditional craftmanship. And the comparative analysis results showed the formula of clay, lime, and sand is about 4:3:3 for the Jiaoshan ancient fort. The result was performed on the repair of this fort with good result. Zhang and Wan [19] investigated the tabia coastal defense fort at Xiaoshi harbor, Huangshan city, Jiangsu province. They found that the formula of the tabia clay and lime is $3: 1$, with about $0.5 \%$ sticky rice soup. They also improved the formula for the fort's restoration. Wu et al. [20] investigated the formula and construction techniques of three tabia coastal defense forts at Minjiang river estuary, Fujian province. Zhou et al. [21] investigated the physical, mechanical and water performance of four tabia coastal defense forts in Guangzhou. All these researches show that the formula of raw materials and craftsmanship of tabia coastal defense forts differs from place to place. This is of great help for us to understand the characteristics of tabia coastal defense forts, and can provide us with support for the necessary restoration project. However, there are few reports on the tabia coastal defense forts in the coastal areas of Zhejiang Province, China. In this study, seven tabia samples were collected from Pinghu coastal defense forts sites, Ningbo coastal defense forts sites, and Wenzhou coastal defense forts sites in Zhejiang Province, China. Surface hardness, compressive strength, density and porosity, component composition, distribution of sand and clay, organic additives, morphology, and aging resistant properties, and capillary water absorption of the tabia samples were studied to have a better understanding of the properties of the tabia coastal defense forts.

Jingyuan coastal defense fort, Pingyuan coastal defense fort, Zhenyuan coastal defense fort, and Hongyuan coastal defense fort are in Zhenhaikou, Ningbo City, Zhejiang Province, China. As a part of the Zhenhaikou Coastal Defense Site, the above four coastal defense forts have been listed as the national key cultural relics in China since 1996. Tianfeigong coastal defense fort and Nanwan coastal defense fort in Zhapu Town, Pinghu City, Zhejiang Province, China, have been listed as the national key cultural relics in China since 2013. Longwan coastal defense fort in Longwan District, Wenzhou City, Zhejiang Province, China, has been listed as a key cultural relic of Wenzhou City since 2002. All these forts were built during 1870s-1890s. The location of these coastal defense forts was marked in Fig. 1, and the collected samples' information was listed in Table 1.

\section{Materials and methods \\ Materials}

The chemicals used in this work were as follows: calcium carbonate, hydrochloric acid, acetate, sodium carbonate anhydrous, sodium hydroxide, copper sulfate anhydrous, trisodium citrate dihydrate, iodine, potassium iodide, zine powder, periodic acid, acetyl acetone, phenolphthalein, and Coomassie Brilliant Blue G-250 dye. All chemicals were procured from Sinopharm Chemical Reagent Co., Ltd., Shanghai.

All the tabia samples were collected from the ground that have fallen off from the coastal defense forts and will not cause damage to the sites. When the samples were cut to reveal a new interface, it was found that the components of the sample JY, PY, ZY, NW, and LW were evenly mixed, while the lime of sample HY and TFG were uneven distributed.

\section{Methods}

\section{Surface Leeb hardness, compressive strength, density} and porosity test

The surface Leeb hardness of the tabia samples was tested using an Equotip 550 Portable Rockwell Leeb D Impact Device (Proceq SA). Five tests were determined and then averaged for each tabia sample. The compressive strength was assessed using a HANDPI electronic tensile testing machine (Yueqing Aidebao Instrument Co., Ltd.). Three tests were performed for each tabia sample and the size of the tabia sample is $3 \times 3 \times 3 \mathrm{~cm}^{3}$. The density and porosity were measured by a QL120C Density Tester (MatsuHaku, Inc.) based on the Archimedes' principle. Three tests were determined and averaged for each tabia sample.

\section{Determination content of calcite, sand, and clay minerals in tabia samples}

The $\mathrm{CaCO}_{3}$ content of tabia samples was calculated based on an acid dissolution method. First, $1.8 \mathrm{~g}$ well dried stone-free tabia was transferred to a conical flask, in which $20 \mathrm{~mL} 1 \mathrm{M} \mathrm{HCl}$ solution was added. Secondly, the flask was shaken for $15 \mathrm{~min}$, to accelerate the chemical reaction: $\mathrm{CaCO}_{3}+2 \mathrm{HCl}=\mathrm{CaCl}_{2}+\mathrm{CO}_{2} \uparrow+\mathrm{H}_{2} \mathrm{O}$. Finally, the volume of $\mathrm{CO}_{2}$ was recorded by a home-made $\mathrm{CO}_{2}$ gas volume measuring instrument and the content $Q_{1}$ of $\mathrm{CaCO}_{3}$ in tabia samples was calculated according to the aforementioned-chemical equation. This process was repeated three times to obtain the average for each tabia sample.

The sand and clay contents were also determined by the acid dissolution method. Briefly, $100 \mathrm{~g}$ well dried stone-free tabia was placed in a beaker with $1000 \mathrm{~mL} 1 \mathrm{M}$ $\mathrm{HCl}$ solution. The excess $\mathrm{HCl}$ solution was removed after the reaction was completed. Then, the sand and clay were 


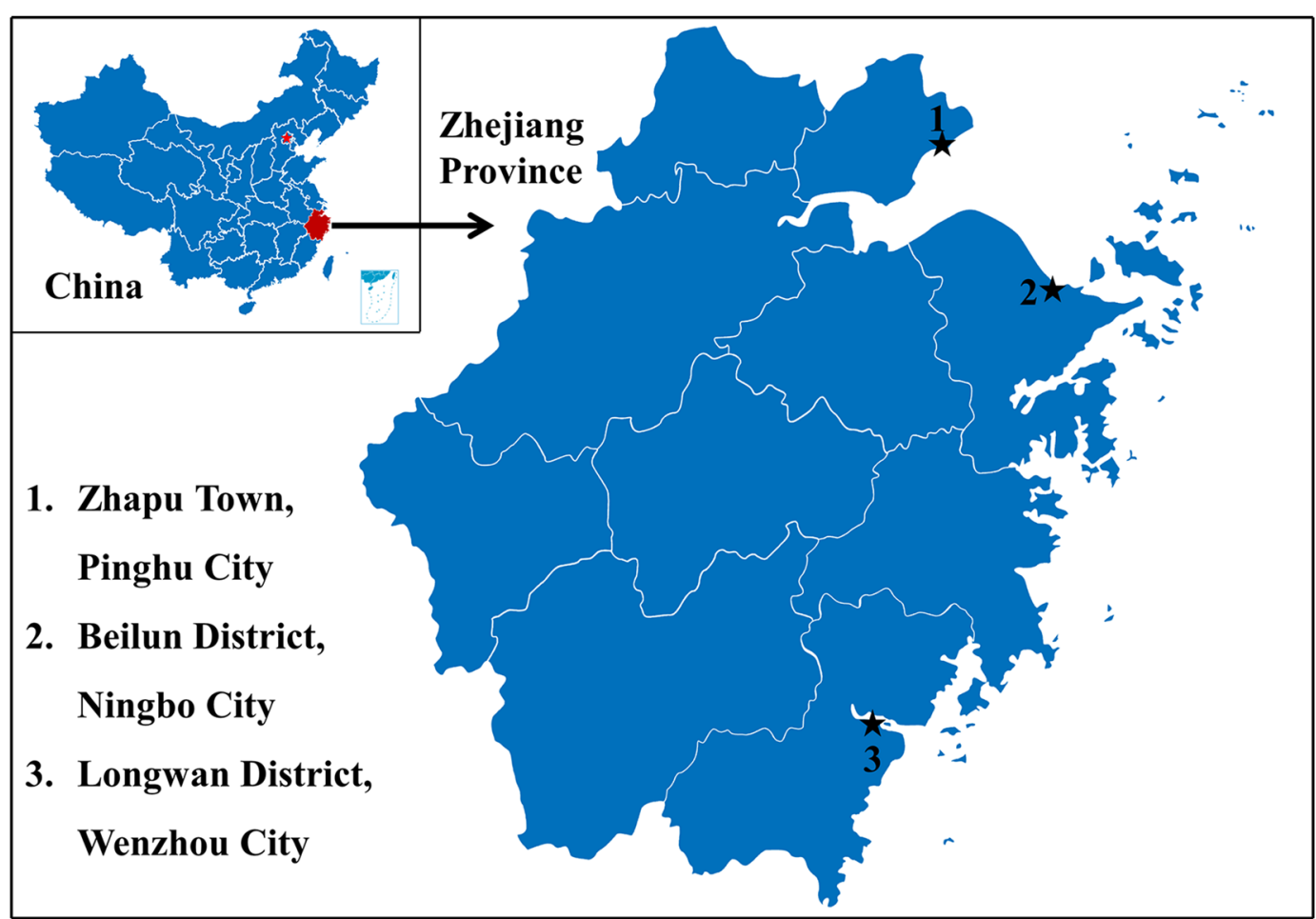

Fig. 1 Location of tabia coastal defense fort sites

washed to $\mathrm{pH}=7$ and dried at $105{ }^{\circ} \mathrm{C}$. After separated by a 200 mesh $(0.075 \mathrm{~mm})$ sieve, the sand with particle size $>0.075 \mathrm{~mm}$ was obtained, and the corresponding sand content $Q_{2}$ could be calculated. Finally, the content of clay (particle size $<0.075 \mathrm{~mm}$ ) $Q_{3}$ was calculated by $1-Q_{1}-Q_{2}$.

\section{Determination of particle size distribution for sand and clay minerals in tabia samples}

The sand of the tabia samples was sifted through a set of sieves in a sequence, including 10 mesh $(2 \mathrm{~mm}), 14$ mesh $(1.4 \mathrm{~mm}), 20$ mesh $(0.85 \mathrm{~mm}), 30$ mesh $(0.6 \mathrm{~mm})$, 40 mesh $(0.425 \mathrm{~mm}), 60$ mesh $(0.25 \mathrm{~mm}), 80$ mesh $(0.18 \mathrm{~mm}), 100$ mesh $(15 \mathrm{~mm}), 120$ mesh $(0.125 \mathrm{~mm}), 150$ mesh $(0.1 \mathrm{~mm})$, and 200 mesh $(0.075 \mathrm{~mm})$. The remains on each sieve were separately weighed and the weight fraction of sands within each size range was obtained. The particle size analysis of the clay minerals in the tabia samples was performed using a BT-2002 laser particle size distribution analyzer (Dandong Bettersize Instrument Co., Ltd.).

\section{Aging test}

The aging test of the tabia samples was performed after the samples were dried at $105{ }^{\circ} \mathrm{C}$ for $4 \mathrm{~h}$. The prepared tabia samples were subjected to aging test through the cycle steps as follows: (1) immersed in water for $1 \mathrm{~h}$; (2) frozen at $-20{ }^{\circ} \mathrm{C}$ for $1 \mathrm{~h}$; (3) dried at $60{ }^{\circ} \mathrm{C}$ for $1 \mathrm{~h}$. The above steps were repeated until the samples were destroyed. The mass changes of the tabia samples were recorded after each cycle.

\section{Determination of organic additives in tabia samples}

A variety of chemical analyses were implemented to detect the organic residues in the samples, including a Coomassie Blue staining test for protein, a Benedict's reagent test for reducing sugar, and a reducing phenolphthalein reagent test for blood, as well as a hydrogen peroxide test for fatty acid ester (i.e., oil). The relevant testing procedures have been documented in Zhang et al. [9]. Additionally, an iodine-potassium iodide reagent was used to detect starch, and the detailed testing procedures have been documented in Zheng et al. [7].

\section{Capillary water absorption test}

The capillary water absorption of the tabia samples was measured by a standardized method [22]. Firstly, the initial mass of the well-prepared tabia sample was weighed and then, the sample bottom was immersed in water. After a specific time period, the sample was taken out, wiped off to remove the water droplets absorbed on the bottom of the sample. Then the 
Table 1 The collection location, built age, and photograph of tabia samples

\begin{tabular}{ll}
\hline Denotation & Collection location \\
JY & Jingyuan Fort, Jinji Mountain, Beilun District, Ningbo City, Zhejiang Province, China
\end{tabular}

JY Jingyuan Fort, Jinji Mountain, Beilun District, Ningbo City, Zhejiang Province, China

Date

Photograph

(1)

PY

Pingyuan Fort, Jinji Mountain, Beilun District, Ningbo City, Zhejiang Province, China

$1880 \mathrm{AD}$

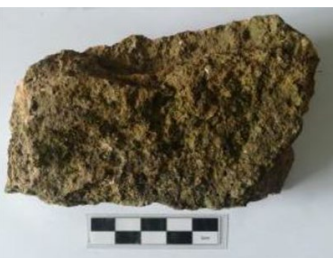

1887 AD

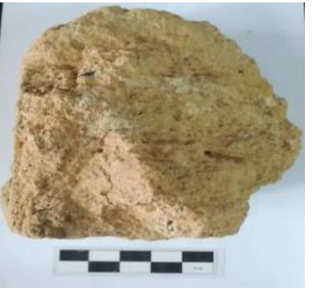

ZY

Zhenyuan Fort, Li Mountain, Beilun District, Ningbo City, Zhejiang Province, China

$1880 \mathrm{AD}$

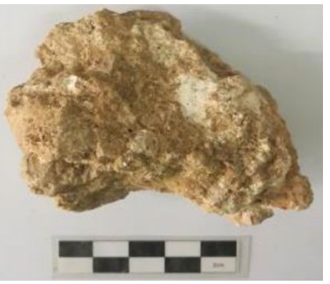

HY

Hongyuan Fort, Li Mountain, Beilun District, Ningbo City, Zhejiang Province, China

$887 \mathrm{AD}$

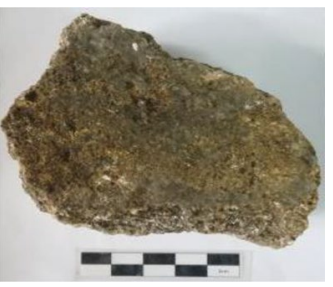

NW

Nanwan Fort, Tang Mountain, Zhapu Town, Pinghu City, Zhejiang Province, China

1894 AD
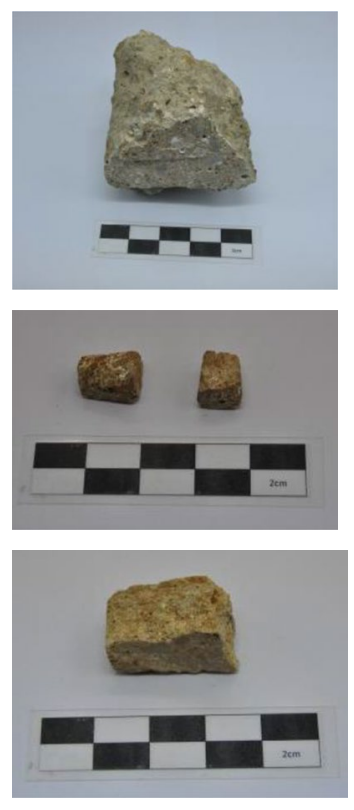
sample was weighed to obtain the mass increase of the sample. Finally, the capillary water absorption coefficient of the tabia samples was calculated.

\section{Morphology and mineral composition analysis}

The morphology of tabia samples was observed by scanning electron microscope (SEM, SU-8010, HITACHI, Japan). The mineral composition of tabia samples was characterized by X-ray diffraction (XRD, RIGAKU/MAX 2550/PC, Germany) using $\mathrm{Cu} \mathrm{K} \alpha$ radiation at $18 \mathrm{kV}$ and $18 \mathrm{~kW}$, with a step size of $0.02^{\circ}$ in the range of $10^{\circ}<2 \theta<70^{\circ}$.

\section{Results and discussion}

The compressive strength, elastic modulus, and surface Leeb hardness of the tabia samples

Figure 2 and Table 2 show the compressive strength of the tabia samples. The samples NW, JY, and HY had higher compressive strength when compared with the other samples. The compressive strength of all these three samples surpassed 6.5 MPa. In this regard, a systematic investigation was performed to figure out why these three tabia samples had such high compressive strength.

Figure 3 shows the strain-stress test results of the tabia samples, and the elastic modulus was calculated using the stress peak divided by the corresponding strain (listed in Table 3). The elastic moduli (over $350 \mathrm{Mpa}$ ) for the

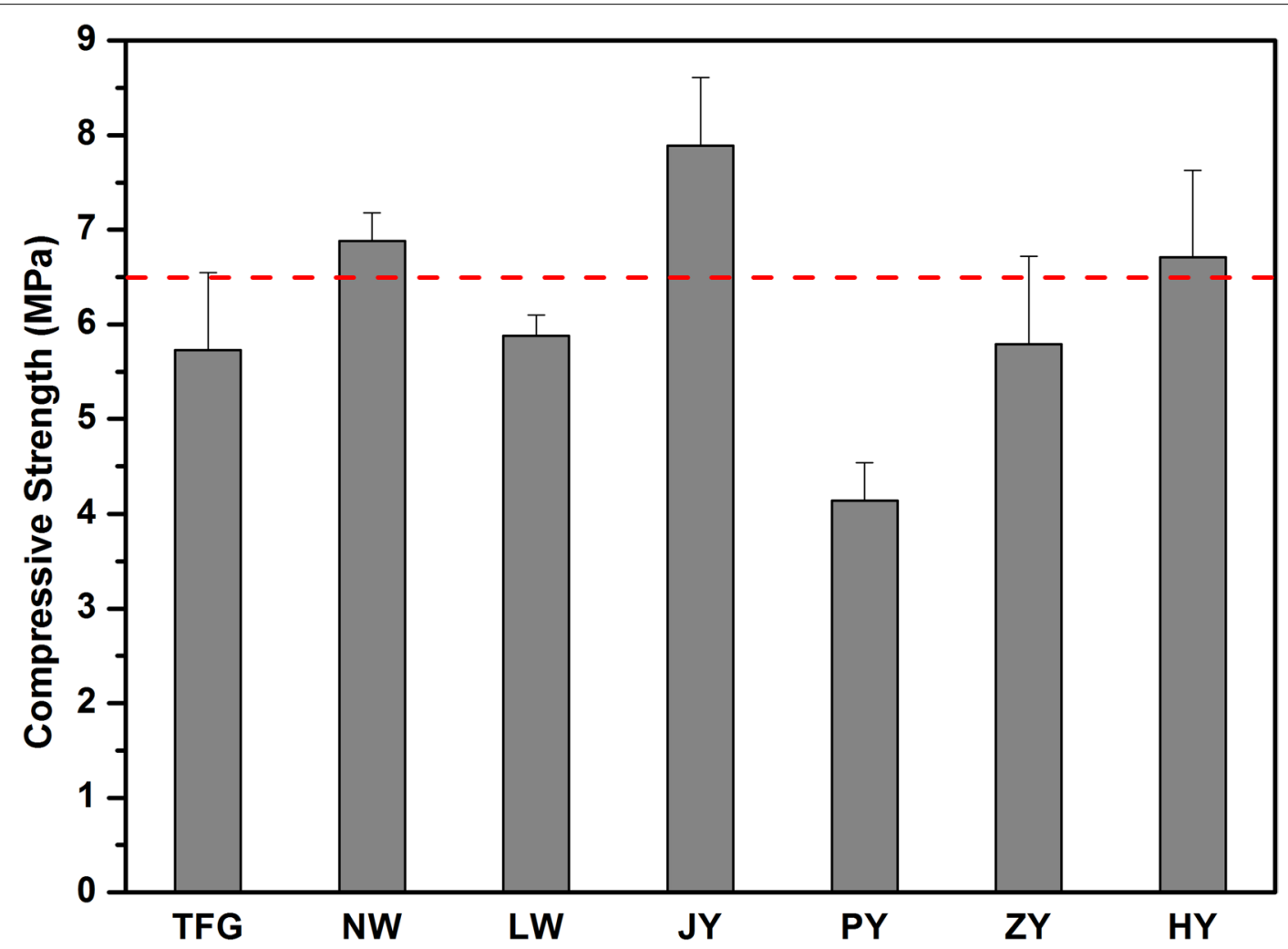

Fig. 2 Compressive strength of tabia samples

Table 2 The compressive strength test results of the tabia samples (MPa)

\begin{tabular}{llllllll}
\hline Sample & TFG & NW & LW & JY & PY & ZY & HY \\
\hline 1 & 4.85 & 7.22 & 5.67 & 7.82 & 3.75 & 6.86 & 5.76 \\
2 & 5.87 & 6.75 & 5.86 & 8.64 & 4.12 & 5.19 & 6.78 \\
3 & 6.47 & 6.67 & 6.11 & 7.21 & 4.55 & 5.32 & 7.59 \\
Average & 5.73 & 6.88 & 5.88 & 7.89 & 4.14 & 5.79 & 6.71 \\
\hline
\end{tabular}




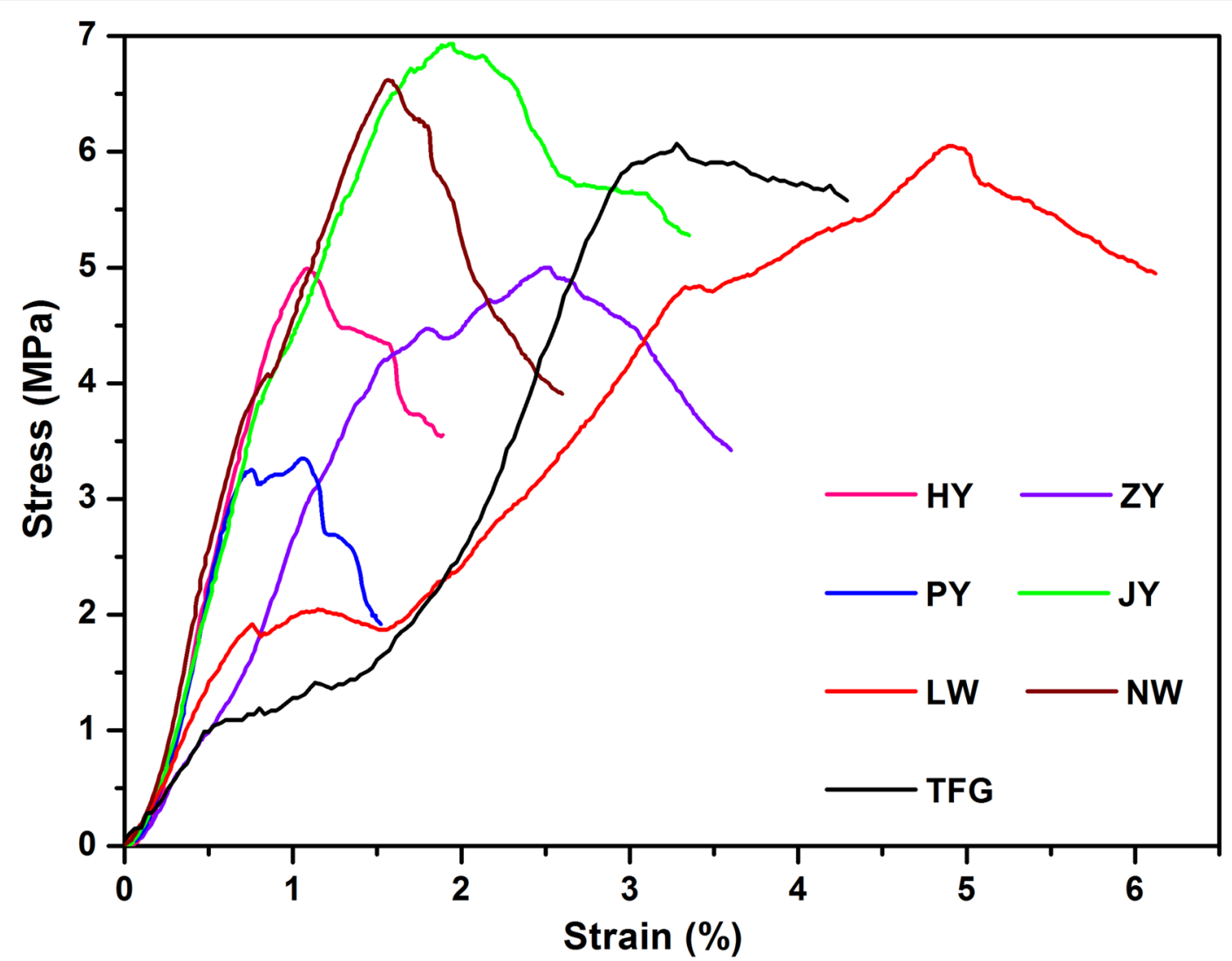

Fig. 3 The stress-strain test of the tabia samples

Table 3 The elastic moduli of the tabia samples (MPa)

\begin{tabular}{llllllll}
\hline Sample & TFG & NW & LW & JY & PY & ZY & HY \\
\hline Elastic modulus & 185 & 424 & 124 & 368 & 319 & 201 & 462 \\
\hline
\end{tabular}

samples NW, JY, and HY were higher when compared with those of the other samples.

The surface Leeb hardness of the tabia samples was among 270-360 HLD (shown in Fig. 4 and Table 4). Compared with the result elastic moduli of the tabia samples, the surface Leeb hardness increased with the elastic modulus. Thus, the portable Leeb hardness tester could be used as a nondestructive method for approximating the elastic modulus of the tabia samples.

\section{The density and porosity of the tabia samples}

Figure 5 and Table 5 show the density and porosity analysis results of the tabia samples. The results show that the density and porosity of the tabia samples were similar. The density of the tabia samples ranged from 1.53 to $1.76 \mathrm{~g} / \mathrm{cm}^{3}$, and the porosity ranged from 41 to $49 \%$. This might indicate that the craftsmanship of these coastal defense forts was alike.

\section{Determination of the contents of calcite, sand and clay} minerals in the tabia samples

The contents of calcite, sand and clay in the tabia samples are depicted in Fig. 6 and Table 6, which fluctuated markedly among different samples. Thermogravimetric analysis method was also used to determine the calcite content of tabia samples. Take sample HY as an example (as shown in Fig. 7), the calculated result of $\mathrm{CaCO}_{3}$ content was $29.8 \%$, which was close to the acid dissolution method (31.7\%). Thus, in this paper, we use the acid dissolution method result for further discussion. The content of sand ranged from 23.1 to $58.5 \%$, the content of calcite ranged from 18.7 to $39.3 \%$, and the 


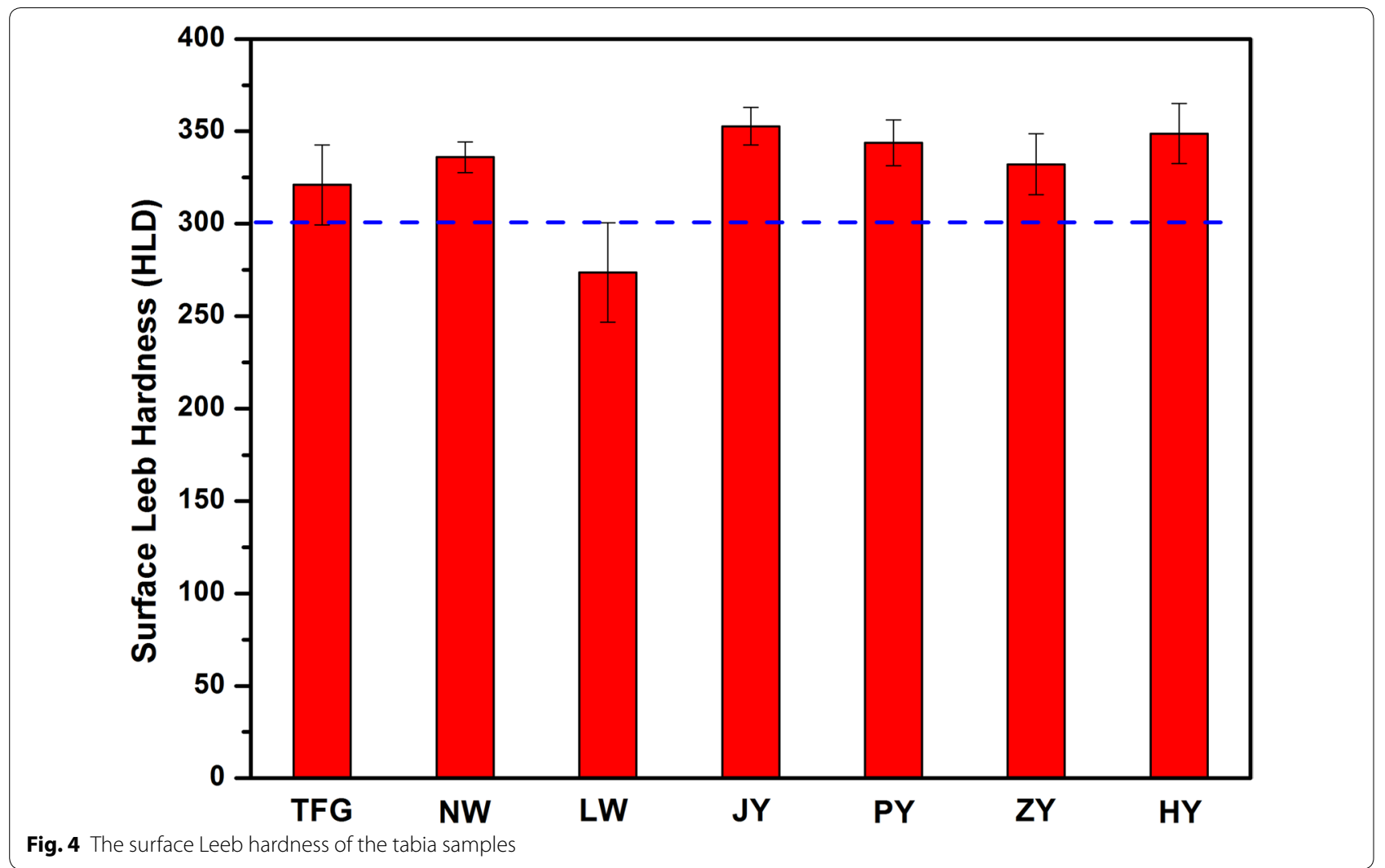

Table 4 The surface Leeb hardness test results of the tabia samples (HLD)

\begin{tabular}{|c|c|c|c|c|c|c|}
\hline Sample & 1 & 2 & 3 & 4 & 5 & Average \\
\hline TFG & 324 & 316 & 343 & 287 & 335 & 321 \\
\hline NW & 328 & 346 & 327 & 341 & 338 & 336 \\
\hline LW & 256 & 241 & 292 & 271 & 308 & 273.6 \\
\hline JY & 360 & 354 & 365 & 343 & 342 & 352.8 \\
\hline PY & 337 & 325 & 354 & 352 & 351 & 343.8 \\
\hline$Z Y$ & 325 & 319 & 361 & 327 & 329 & 332.2 \\
\hline $\mathrm{HY}$ & 346 & 360 & 322 & 354 & 362 & 348.8 \\
\hline
\end{tabular}

content of clay minerals ranged from 22.3 to $53.5 \%$. The differences among the tabia samples in the contents of calcite, sand, and clay indicated the variance in the craftsmanship. The ratio of calcite, sand, and clay in samples JY, NW, and HY (circled in red), was around $1: 1: 1$. These results indicate that the appropriate ratio of sand, calcite, and clay could be an essential factor leading to the high compressive strength of tabia samples. in this regard, it is necessary to study the influence of the grain size distribution of sand on the high compressive strength of the tabia samples, because sand served as the aggregate and took up a large proportion of the tabia.

\section{Determination of the grain size distribution of sand} and clay minerals in the tabia samples

Figure 8 and Table 7 show the grain size distribution of sand in the tabia samples. The grain size for each tabia sample could be categorized as: (1) small $<0.18 \mathrm{~mm}$; (2) middle $=0.18-0.85 \mathrm{~mm}$; and (3) large $>0.85 \mathrm{~mm}$. The ratios of small size mass, middle size mass, and large size mass of sand in the tabia samples were donated as $R_{s}, R_{m}$, and $R_{l}$, respectively. The $R_{s}, R_{m}$, and $R_{1}$ of the tabia samples are listed in Table 8 . It is noted that all the $R_{m}$ values of samples NW, JY, and HY were below $50 \%$. The $R_{m / 1}$ and $R_{m / s}$ were calculated by dividing $R_{m}$ by $R_{l}$ and $R_{s}$, respectively. All the $R_{m / l}$ and $R_{m / s}$ values 


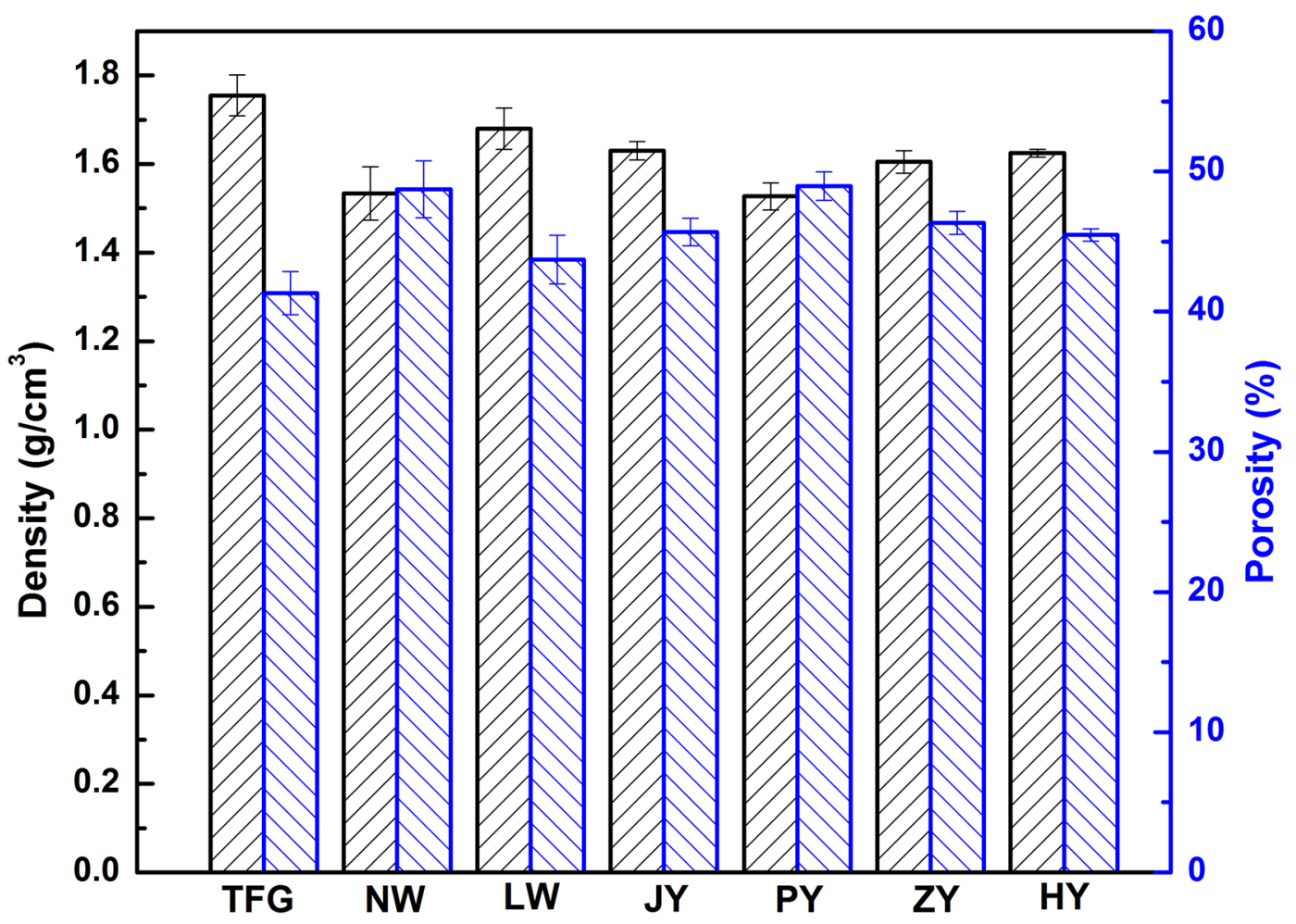

Fig. $\mathbf{5}$ The density and porosity of the tabia samples

Table 5 Density and porosity test results of tabia samples

\begin{tabular}{|c|c|c|c|c|c|c|c|c|}
\hline \multirow[t]{2}{*}{ Sample } & \multicolumn{4}{|c|}{ Density $\left(\mathrm{g} / \mathrm{cm}^{3}\right)$} & \multicolumn{4}{|c|}{ Porosity (\%) } \\
\hline & 1 & 2 & 3 & Average & 1 & 2 & 3 & Average \\
\hline TFG & 1.808 & 1.723 & 1.734 & 1.755 & 39.54 & 42.39 & 42.02 & 41.32 \\
\hline NW & 1.593 & 1.536 & 1.472 & 1.534 & 46.73 & 48.64 & 50.80 & 48.72 \\
\hline LW & 1.659 & 1.648 & 1.734 & 1.680 & 44.54 & 44.90 & 41.72 & 43.72 \\
\hline JY & 1.607 & 1.636 & 1.647 & 1.630 & 46.79 & 45.30 & 44.94 & 45.68 \\
\hline PY & 1.542 & 1.547 & 1.492 & 1.527 & 48.45 & 48.29 & 50.12 & 48.95 \\
\hline$Z Y$ & 1.576 & 1.623 & 1.616 & 1.605 & 47.29 & 45.75 & 45.97 & 46.34 \\
\hline HY & 1.617 & 1.634 & 1.623 & 1.625 & 45.96 & 45.09 & 45.36 & 45.47 \\
\hline
\end{tabular}

of samples NW, JY, and HY were below 2.0 (shown in Fig. 9). These results indicate the relatively disperse distribution of sand would enhance the mechanical strength of the tabia.

The grain size distribution of clay minerals had similarity among the tabia samples, which was mainly concentrated in 20-40 $\mu \mathrm{m}$ (Fig. 10). This might indicate that the clay minerals used in these tabia coastal defense forts was processed by similar treatments.
The detection of organic additives in the tabia samples The detection was performed for the organic additives including oil, protein, blood, sugar, and starch in the tabia samples. Among these organic additives, oil, protein, blood, and sugar were not detected in any of the tabia samples. For the starch test, the absorbance at $533.4 \mathrm{~nm}$ of the obtained solution of tabia samples (shown in Fig. 11) is shown in Table 9. The absorbance of samples JY, PY, and ZY was $0.128,0.198$, and 0.172 , respectively, 


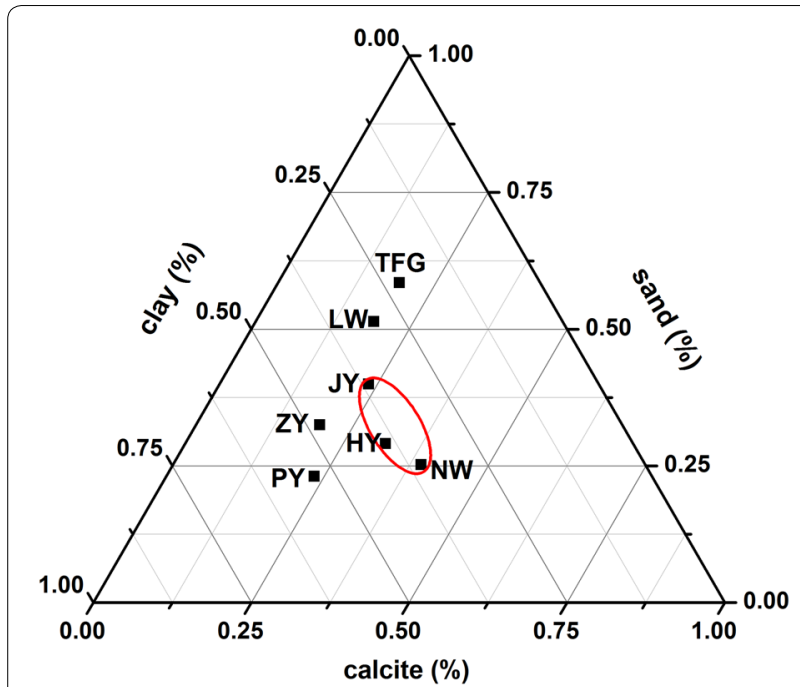

Fig. 6 The contents of $\mathrm{CaCO}_{3}$, sand, and clay minerals in the tabia samples

Table 6 Sand, clay minerals, and calcite weight content (\%) of tabia samples

\begin{tabular}{llll}
\hline Sample & Calcite & Sand & Clay minerals \\
\hline TFG & 19.2 & 58.5 & 22.3 \\
NW & 39.3 & 25.2 & 35.5 \\
LW & 18.7 & 51.4 & 29.9 \\
JY & 23.6 & 40.0 & 36.4 \\
PY & 23.4 & 23.1 & 53.5 \\
ZY & 19.6 & 32.5 & 47.9 \\
HY & 31.7 & 29.1 & 39.2 \\
\hline
\end{tabular}

while the limit of detection (LOD) for this method was 0.096, as reported in [7]. This demonstrated that there was sticky rice in samples JY, PY, and ZY. The samples without starch might originally have it, but the starch was degraded. Herein, the detection of sticky rice in the tabia samples needs further clarification.

\section{The morphology and mineral composition analysis}

Figure 12 shows the morphology of tabia samples. The clay minerals, sand, and calcite particles were found in samples TFG (Fig. 12a), LW (Fig. 12c), JY (Fig. 12d), PY (Fig. 12e), and ZY (Fig. 12f). While the hydraulic materials C-S-H fibers were found in samples NW (Fig. 12b) and HY (Fig. 12g). These C-S-H fibers might be generated by the chemical reaction between lime, quartz, and water: $\mathrm{SiO}_{2}+\mathrm{CaO}+\mathrm{H}_{2} \mathrm{O} \rightarrow \mathrm{C}-\mathrm{S}-\mathrm{H}$, and these hydraulic materials $\mathrm{C}-\mathrm{S}$-H fibers could enhance the hardness of the tabia.

Figure 13 shows the XRD test results of the tabia samples. The main minerals of tabia samples are quartz and calcite. There are also other minerals, for example albite, muscovite, katoite, vaterite, sanidine, and kaolinite observed in the tabia samples. The similar minerals composition of sample JY (Fig. 13d), PY (Fig. 13e), and ZY (Fig. 13f) may indicate the same source of the soil of the three forts, which is different from the HY fort. The mineral difference between other tabia samples indicating the different sources of the soil.

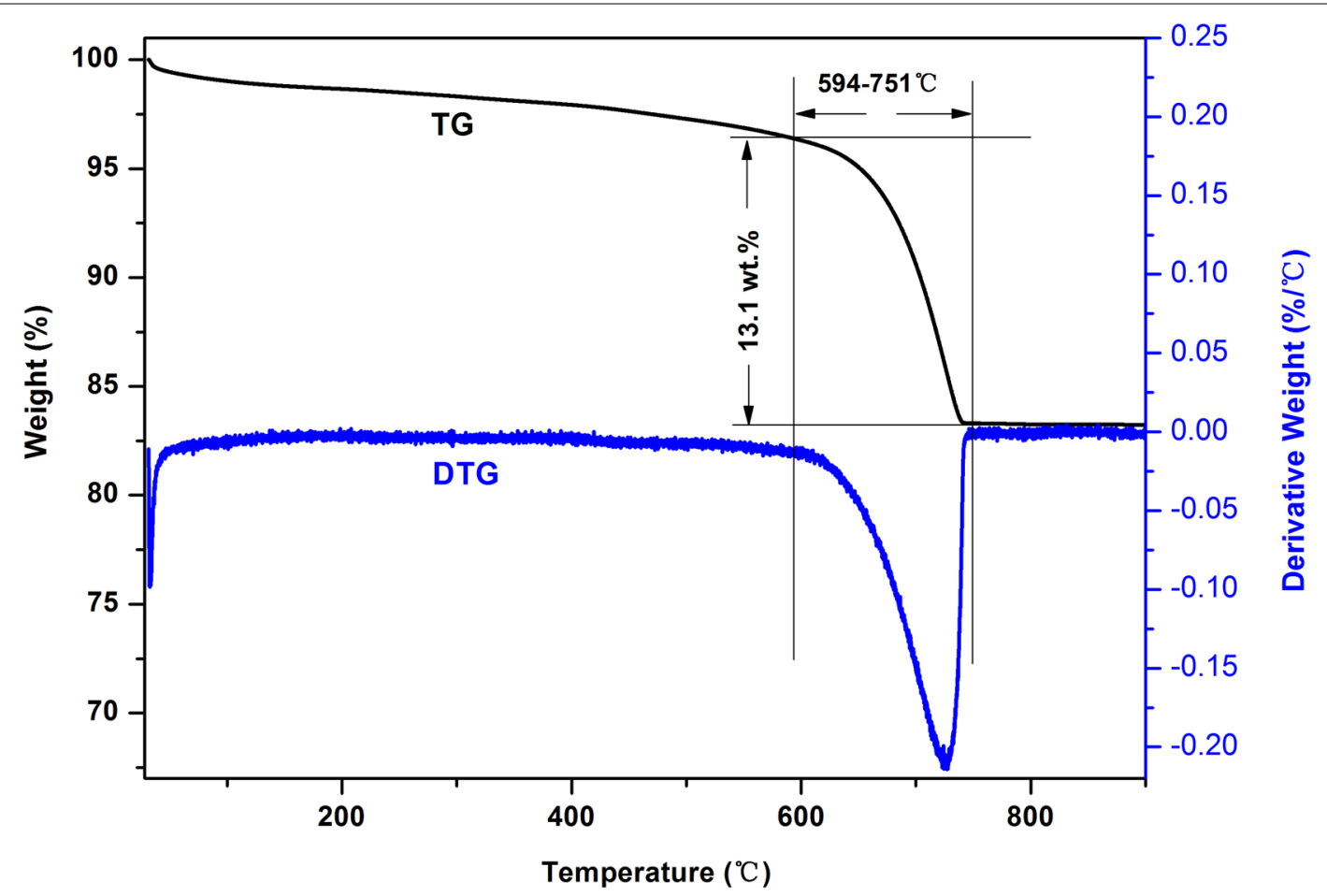

Fig. 7 Characteristic TG-DTG curve of sample HY 


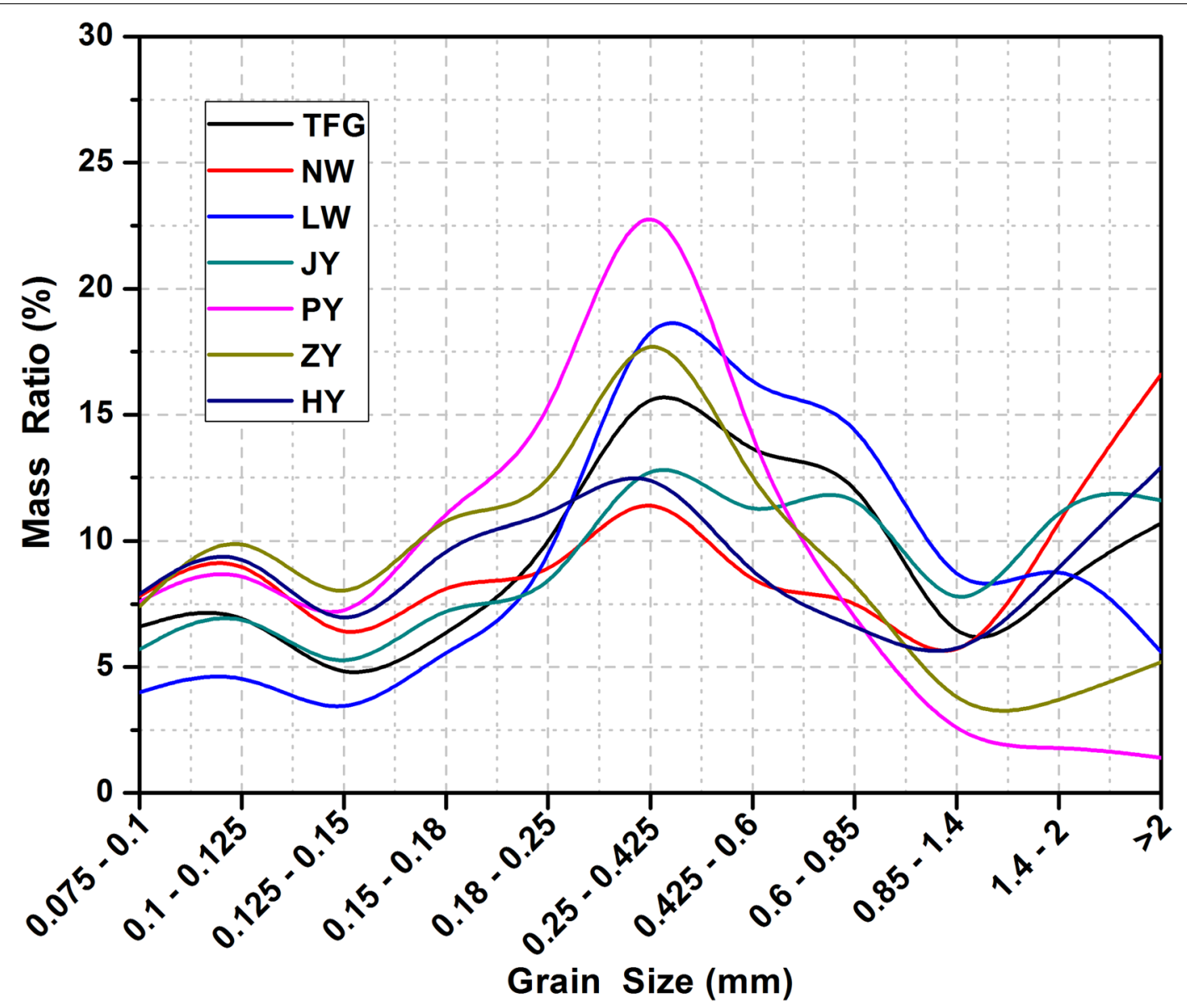

Fig. 8 The grain size distribution of sand in the tabia samples

Table 7 Sand grain size weight distribution (\%) test results of tabia samples

\begin{tabular}{|c|c|c|c|c|c|c|c|}
\hline Mesh & TFG & NW & LW & JY & PY & $Z Y$ & HY \\
\hline$>10$ & 10.7 & 16.6 & 5.6 & 11.6 & 1.4 & 5.2 & 12.9 \\
\hline $10-14$ & 8.5 & 11.0 & 10.1 & 12.4 & 1.9 & 3.6 & 9.0 \\
\hline $14-20$ & 4.1 & 3.7 & 6.5 & 5.2 & 1.7 & 2.6 & 4.7 \\
\hline $20-30$ & 13.9 & 8.5 & 16.2 & 13.6 & 6.9 & 8.9 & 6.7 \\
\hline $30-40$ & 12.5 & 7.3 & 15.0 & 9.8 & 12.6 & 11.3 & 8.1 \\
\hline $40-60$ & 18.0 & 13.3 & 21.8 & 14.9 & 27.7 & 21.1 & 13.9 \\
\hline $60-80$ & 8.9 & 7.8 & 7.3 & 6.9 & 13.1 & 10.4 & 10.6 \\
\hline $80-100$ & 6.4 & 9.0 & 5.9 & 8.1 & 11.9 & 12.0 & 10.4 \\
\hline $100-120$ & 3.7 & 4.8 & 2.4 & 3.9 & 5.5 & 6.2 & 5.2 \\
\hline $120-150$ & 7.8 & 10.3 & 5.2 & 7.9 & 9.6 & 11.4 & 10.6 \\
\hline 150-200 & 6.6 & 7.8 & 4.0 & 5.7 & 7.6 & 7.4 & 7.9 \\
\hline
\end{tabular}

The aging test of the tabia samples

The mass ratio of the tabia samples after each aging cycle is shown in Fig. 14. The cycles of $100 \%$ residual mass ratio were taken as the aging resistance capability, and the aging resistance capability of the samples increased with the increase of the calcite content. Sample NW with the highest calcite content of $39.3 \%$ had the highest aging resistance capability (87 cycles). However, sample 
Table 8 The $R_{s}, R_{m}$, and $R_{l}$ of the tabia samples

\begin{tabular}{llllllll}
\hline & TFG & NW & LW & JY & PY & ZY & HY \\
\hline$R_{s}$ & 24.5 & 31.9 & 17.5 & 25.6 & 34.6 & 37.0 & 35.1 \\
$R_{m}$ & 53.3 & 36.9 & 60.3 & 45.2 & 60.3 & 51.7 & 38.3 \\
$R_{l}$ & 23.3 & 31.3 & 22.2 & 29.2 & 5.0 & 11.4 & 26.6 \\
\hline
\end{tabular}

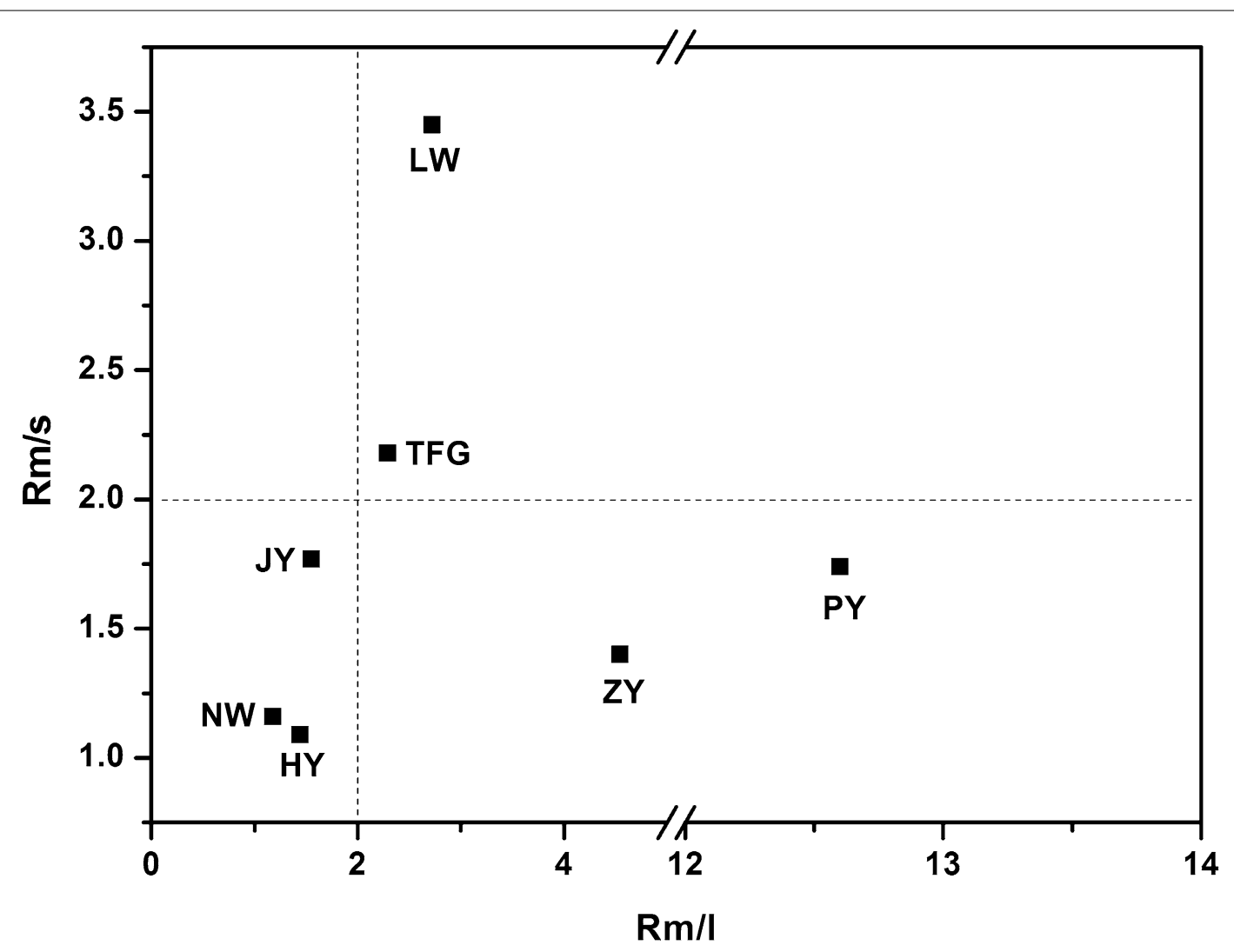

Fig. 9 The $R_{m / l}$ and $R_{m / s}$ of the tabia samples

HY with the calcite content of $31.7 \%$ had a lower aging resistance capability (34 cycles), which is lower than that of sample JY (72 cycles with $23.6 \%$ calcite), PY (68 cycles with $23.2 \%$ calcite) and ZY (56 cycles with $19.2 \%$ calcite). This observation was due to the inhomogeneous distribution of lime in sample HY. Comparing the aging test results with the mechanical properties results, composition test results, density and porosity results, and particle size distribution results, we found that sample NW, JY, and PY that with higher content of calcite, and lower content of sand (which could cause lower density) had higher aging resistance capability. Thus, tabia with wellmixed raw materials, high content of lime, low content of sand will have a high performance of aging resistance capability. The aging resistance test could be used as a method to evaluate the tabia's craftsmanship of the tabia.

\section{The capillary water absorption test of the tabia samples}

Figure 15 shows the capillary water absorption quantity $\Delta \mathrm{m}$ of tabia samples at different absorption time, $t$. The capillary water absorption coefficient could be calculated from the equation $\Delta \mathrm{m}=C * A t^{0.5}$, where $C$ is the water absorption coefficient and $A$ is the bottom area of the tabia sample [23]. The results of capillary water absorption coefficient was divided into three parts. For sample TFG (with porosity $41.32 \%$ ), the capillary water absorption coefficient is $0.024 \mathrm{~g} / \mathrm{cm}^{2} \mathrm{~min}^{0.5}$. For samples JY, ZY, 


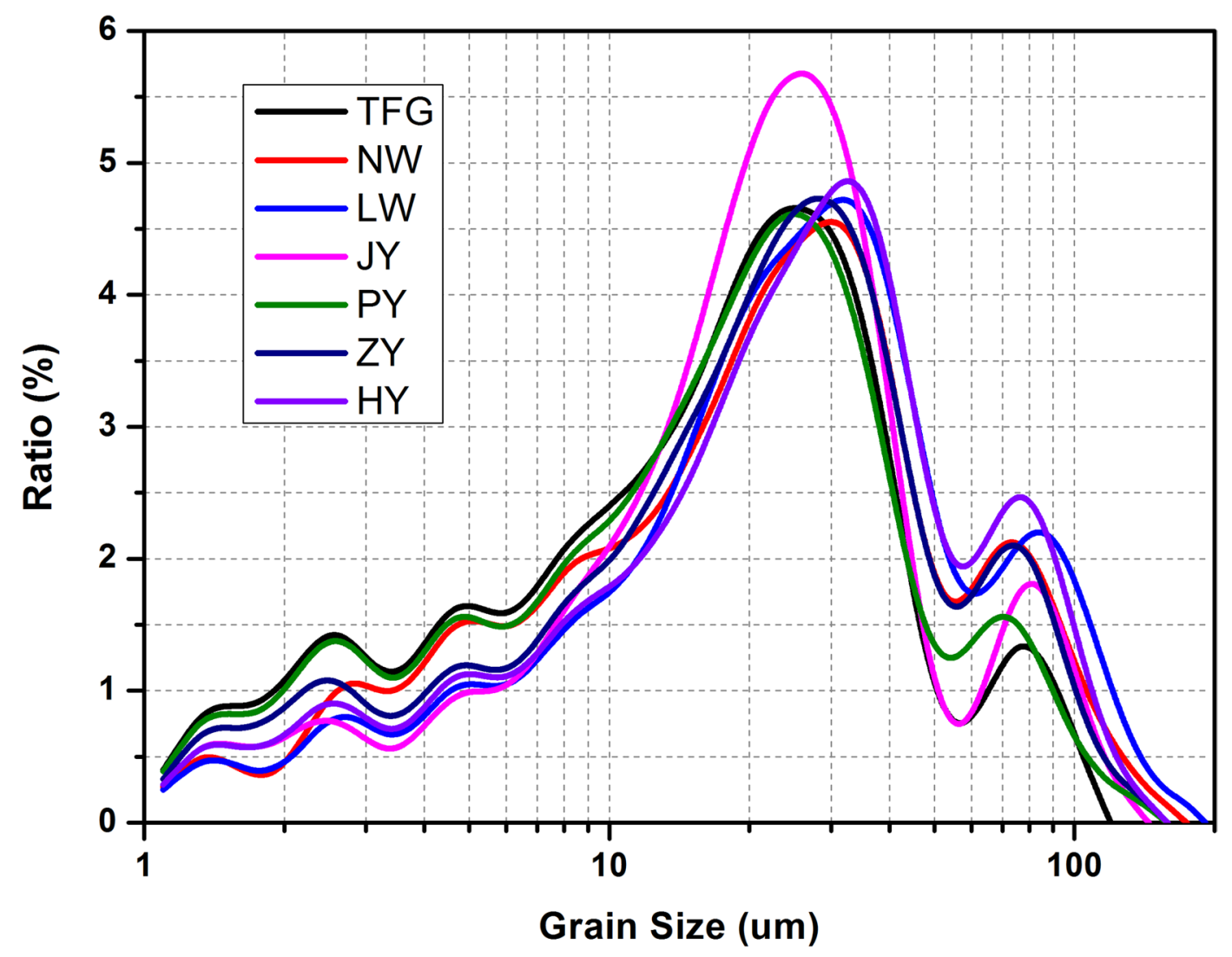

Fig. 10 The grain size distribution of clay minerals in the tabia samples

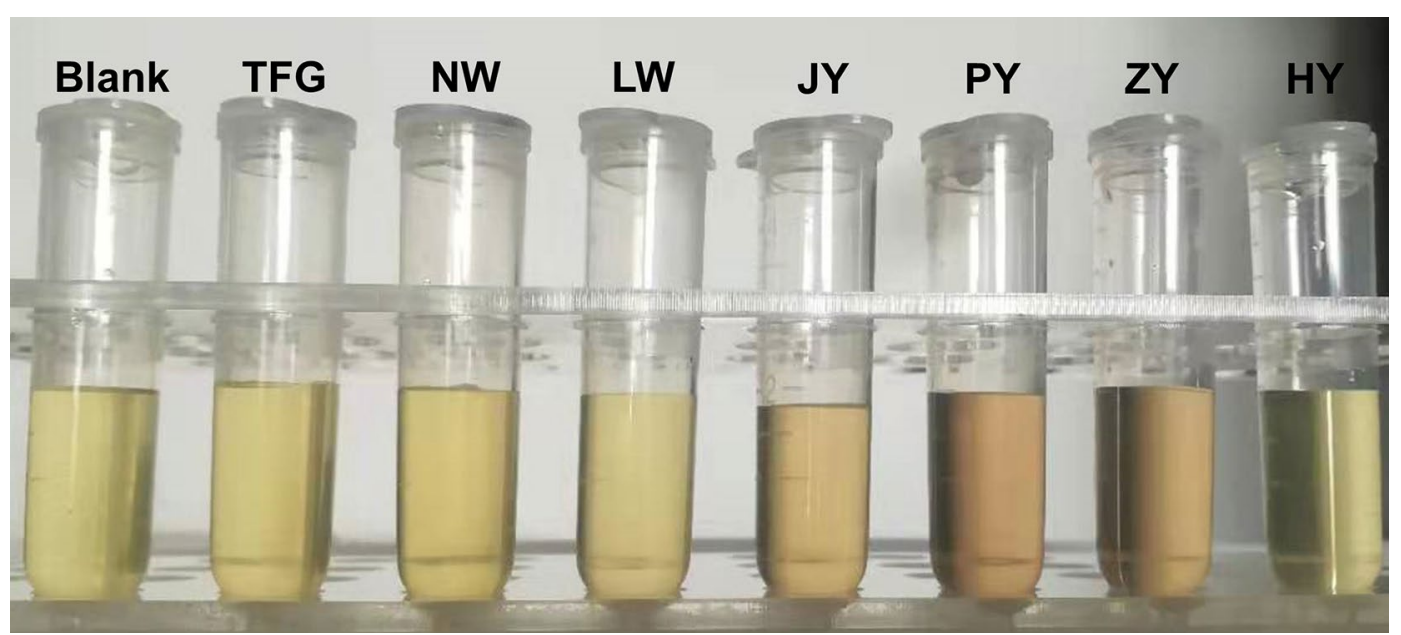

Fig. 11 The starch test results for the tabia samples

LW, and HY (with porosity from 43.72 to $46.34 \%$ ), the corresponding capillary water absorption coefficients were from 0.044 to $0.059 \mathrm{~g} / \mathrm{cm}^{2} \mathrm{~min}^{0.5}$, much higher than that of sample TFG. Samples NW and PY (with porosity from 48.72 to $48.95 \%$ ) had a similar capillary water absorption coefficient $0.077-0.078 \mathrm{~g} / \mathrm{cm}^{2} \mathrm{~min}^{0.5}$. These results show that the capillary water absorption coefficient of the tabia samples increase with the porosity. 
Table 9 The organic additives test results of the tabia samples

\begin{tabular}{lllllllll}
\hline Sample & pH & Oil & Protein & Blood & Sugar & Bubbles & Absorbance & Starch \\
\hline TFG & 7 & - & - & - & - & ++ & 0.083 & - \\
NW & 9 & - & - & - & - & +++ & 0.086 & - \\
LW & 7 & - & - & - & - & + & 0.073 & + \\
JY & 7 & - & - & - & - & + & 0.128 & + \\
PY & 7 & - & - & - & - & + & 0.198 & + \\
ZY & 7 & - & - & - & - & + & 0.063 & + \\
HY & 8 & - & - & - & - & & + \\
\hline
\end{tabular}

-: Negative reaction; + : Weak positive reaction; $++:$ Median positive reaction; $+++:$ Strong positive reaction
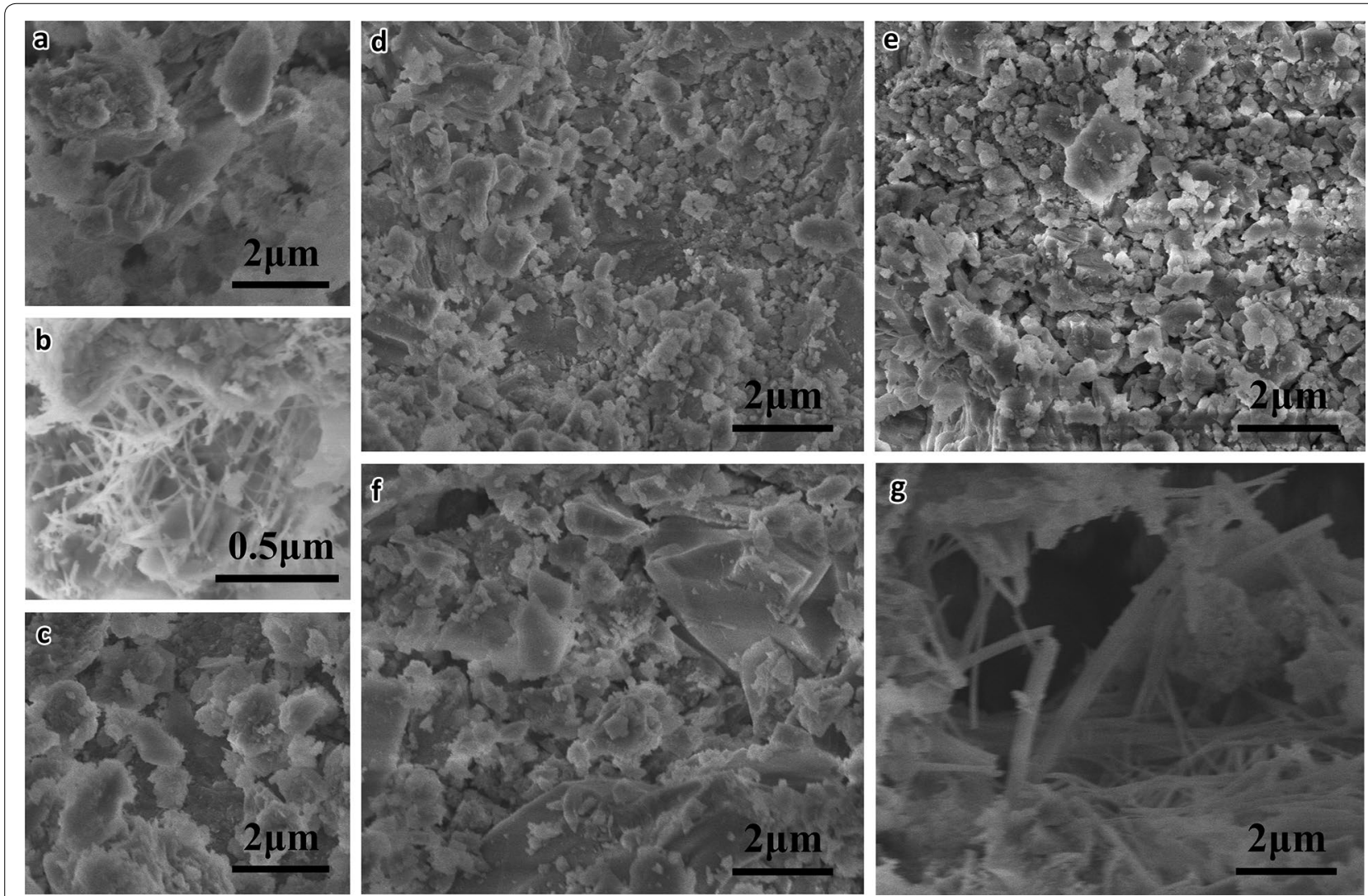

Fig. 12 SEM images of the tabia samples: a TFG, b NW, $\mathbf{c} L W, \mathbf{d} J Y, \mathbf{e} P Y, \mathbf{f} Z Y$, and $\mathbf{g} H Y$

\section{Conclusions}

In this work, a comprehensive method was established for studying traditional tabia samples from the Coastal Defense Forts Sites in Zhejiang Province, China, which included evaluating surface hardness, compressive strength, density and porosity, component composition, distribution of sand and clay, organic additives, morphology, and aging resistant properties, and capillary water absorption. The superior strength in tabia samples NW, JY, and HY was determined to be largely related to the following factors: (1) a suitable mass ratio of sand: lime: clay, i.e.,-around 1:1:1; (2) an appropriate particle size ratio of sand; and (3) the formation of the hydraulic materials $\mathrm{C}-\mathrm{S}-\mathrm{H}$. Pertaining to the 


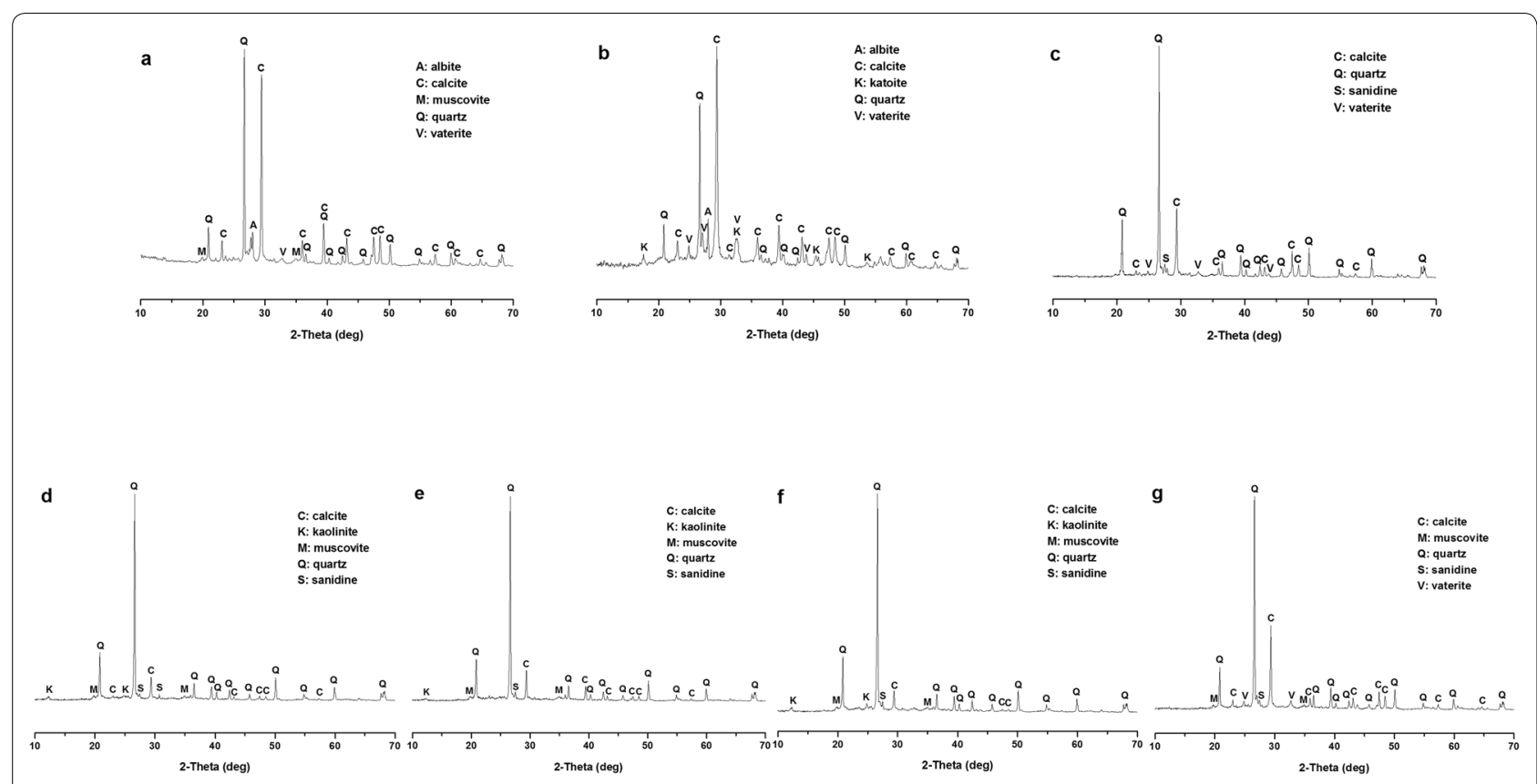

Fig. $13 X R D$ results of the tabia samples: a TFG, $\mathbf{b} N W, \mathbf{c} L W, \mathbf{d} J Y, \mathbf{e} P Y, \mathbf{f} Z Y$, and $\mathbf{g} H Y$

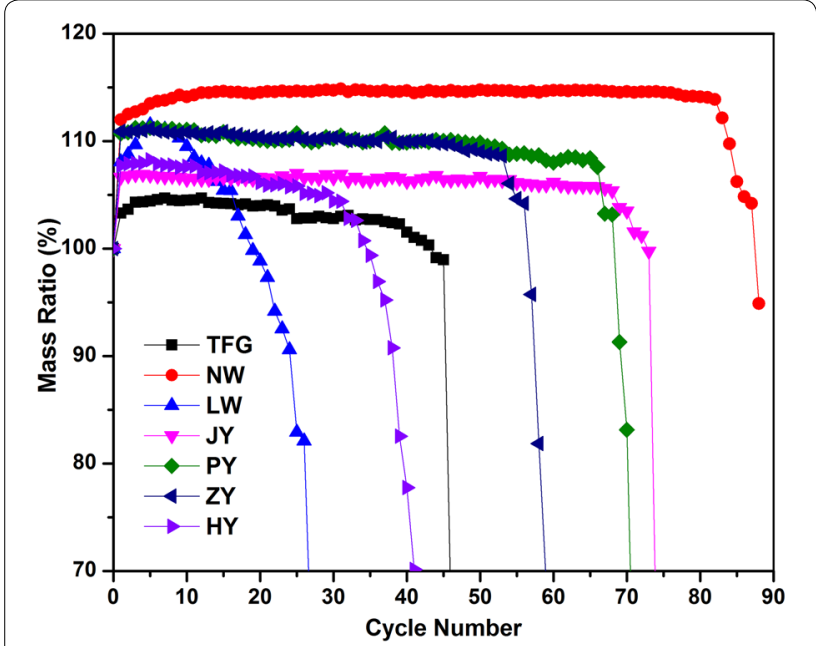

Fig. 14 The aging test results of the tabia samples

craftsmanship of the tabia, the well distributed components could be beneficial to improve the performance of the tabia. The sticky rice components were detected in some of the tabia samples. However, whether sticky rice has been added to other tabia samples needs further study. These findings are fundamentally important for a better understanding of the craftsmanship of the Coastal Defense Forts Sites tabia, which could provide essential guidance for protection and restoration of the tabia relics.

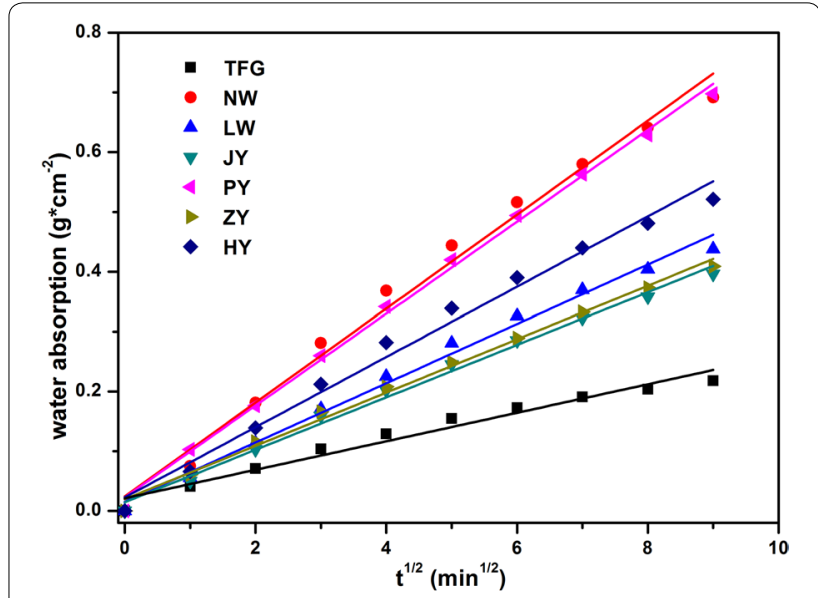

Fig. 15 The capillary water absorption test results of the tabia samples

\section{Acknowledgements}

The authors are thankful to co-workers during the samples' collection.

\section{Authors' contributions}

CZ:Writing-original draft. BZ: Writing-review and editing, supervision. BC: Resources, writing-review and editing. GL: Resources, writing-review and editing. All authors read and approved the final manuscript.

\section{Funding}

This work was supported by the Conservation Science and Technology Project of Zhejiang Provincial Administration of Cultural Heritage (2016). 


\section{Availability of data and materials}

The datasets used and/or analyzed during the current study are available from the corresponding author on reasonable request.

\section{Ethics approval and consent to participate}

This article does not contain any studies with human participants or animals performed by any of the authors.

\section{Consent for publication}

The consent for the publication of details and images in the manuscript are obtained from all participants.

\section{Competing interests}

The authors declare that they have no competing interests.

\section{Author details}

${ }^{1}$ Department of Cultural Heritage and Museology, Zhejiang University, Hangzhou 310028, People's Republic of China. ${ }^{2}$ Department of Chemistry, Zhejiang University, Hangzhou 310027, People's Republic of China. ${ }^{3}$ Zhejiang Provincial Institute of Cultural Relics and Archaeology, Hangzhou 310014 People's Republic of China. ${ }^{4}$ Ningbo Institute of Cultural Relics and Archaeology, Ningbo 315012, People's Republic of China.

Received: 9 June 2020 Accepted: 15 October 2020

Published online: 02 November 2020

\section{References}

1. Liu X, Yang S, Zhang B. Studies of rammed earthen foundations from the archaeological site of the Shang city at Zhengzhou. Sci Conserv Archaeol. 2016;28(4):106-12 (in Chinese).

2. Shui B. Preliminary study on lime-soil in ancient rammed earth construction site in China. Master's Thesis, Northwest University (Xi'an). 2012. (in Chinese)

3. Yao Q, LV D. On historical evolution of the ancient Tongwan city \& its architecture J Yan'an Univ (Soc Sci Ed). 2004:26(2):126-8 (in Chinese).

4. Cen D, Chen X, Wang Z. Excavation report of Xinwuwan tomb in Xishui county. Jianghan Archaeol. 2011;51:66-73 (in Chinese).

5. Pu S. The Yuanzitai North Yan tomb in Chaoyang county Liaoning province. Cult Relics. 1994;11:43-7 (in Chinese).

6. Tie F. Conservation and restoration of wall paintings of early Western Han Dynasty -investigation of conservation history and actuality. Sci Conserv Archaeol. 2004;16(1):47-51 (in Chinese).

7. Zheng $\mathrm{Y}$, Zhang $\mathrm{H}$, Zhang $\mathrm{B}$. A new method in detecting the sticky rice component in traditional Chinese tabia. Archaeometry. 2016;58(S1):218-29

8. Li J, Zhang B. Why ancient Chinese people like to use organic-inorganic composite mortars? - Application history and reasons of organic-inorganic mortars in ancient Chinese buildings. J Archaeol Method Theory. 2019:26(2):502-36.
9. Zhang K, Zhang H, Fang S, Li J, Zheng Y, Zhang B. Textual and experimental studies on the compositions of traditional Chinese organic-inorganic mortars. Archaeometry. 2014;56(S1):100-15.

10. Feng $L$. Research of Qing Dynasty Zhejiang coastal defense Fort. Master's Thesis, Hebei Normal University. 2015. (in Chinese).

11. Xu J. Outline of Coastal Defense. 1887. https://103.242.200.9/ancientboo k/portal/readPage/3A1CE242C21C458BBF9369BBE6D9581C/1/index .do?heightWord=\%25E6\%25B4\%258B\%25E9\%2598\%25B2\%25E8\%25AF \%25B4\%25E7\%2595\%25A5. (in Chinese).

12. Chen $Y$, Wang $X$, Yang $S$, Guo Q. A preliminary study of the freeze-thaw cycle on the structure of earthen sites with different salts. Dunhuang Res. 2013;1:98-107+132 (in Chinese).

13. Chen W, Guo Z, Xu Y, Chen P, Zhang S, Ye F. Laboratory tests on rammed earth samples of earthen sites instilled by reinforcement material $\mathrm{SH}$. Chin J Geotech Eng. 2015;37(8):1517-23 (in Chinese).

14. Pu T, Chen W, Du Y, Li W, Su N. Snowfall-related deterioration behavior of the Ming Great Wall in the eastern Qinghai-Tibet Plateau. Nat Hazards. 2016;84(3):1539-50.

15. Qu J, Cheng G, Zhang K, Wang J, Zu R, Fang H. An experimental study of the mechanisms of freeze/thaw and wind erosion of ancient adobe buildings in Northwest China. Bull Eng Geol Environ. 2007;66(2):153-9.

16. Shao M, Li L, Wang S, Wang E, Li Z. Deterioration mechanisms of building materials of Jiaohe ruins in China. J Cult Herit. 2013;14(1):38-44.

17. Li N, Zhang Z, Wang D. Primary study on the "Sanhe Tu" from the Haizi and Weizi Emplacements in Tianjing Dagu site. Sci Conserv Archaeol. 2008;20(2):46-51 (in Chinese).

18. Yuan $R$, Song $X$, Li J, Ding C. Research on rammed earth composition and building craftsmanship in ancient emplacement at Jiaoshan. Sci Conserv Archaeol. 2010;22(2):18-22 (in Chinese).

19. Zhang H, Wan L. Research on the optimal formula of "Lime-soil" for restoration of the Xiaoshi harbor fort site at Huangshan. Jiangyin Sci Conserv Archaeol. 2010;22(2):23-6 (in Chinese).

20. Wu R, Bao Q, Ji H. Research on material and manufacturing process of ancient trinity of coastal defence emplacements in the Minjiang River Estuary. Ind Constr. 2018;48(5):127-33 (in Chinese)

21. Zhou S, Chen H, Li S, Zhang F, Liu X. Engineering characteristics analysis of four guangzhou artillery batteries of Qing dynasty. Herit Observ. 2019:4(2):136-8 (in Chinese).

22. ISO 15148. Preview Hygrothermal performance of building materials and products-Determination of water absorption coefficient by partial immersion. 2002

23. Zhang H, Shi M, Shen W, Li Z, Zhang B, Liu R, Zhang R. Damage or protection? The role of smoked crust on sandstones from Yungang Grottoes. J Archaeol Sci. 2013:40(2):935-42.

\section{Publisher's Note}

Springer Nature remains neutral with regard to jurisdictional claims in published maps and institutional affiliations.

\section{Submit your manuscript to a SpringerOpen ${ }^{\circ}$ journal and benefit from:}

- Convenient online submission

$\checkmark$ Rigorous peer review

- Open access: articles freely available online

- High visibility within the field

- Retaining the copyright to your article

Submit your next manuscript at springeropen.com 